\title{
Fading Sugammadex, or Just Cautiously (re) Considered?!
}

\author{
Sanda-Maria Copotoiu*
}

\author{
Deputy Editor
}

University of Medicine and Pharmacy of Tirgu Mures, 38 Gheorghe Marinescu street, Tirgu Mures, 540139, Romania

Sugammadex, a synthetic cyclodextrin sodium salt, was heralded and initially marketed as the first selective relaxant binding agent (SRBA) designed to reverse rocuronium [1]. This chemically modified cyclodextrin basically swallowed rocuronium removing it from the effector site, which was a "paradigm shift" from the then current methodology [2]. Following the launch of rocuronium and the rapidly spreading practice of intubation on rocuronium in rapid sequence instead of succinylcholine, a need to reverse muscle relaxation in case of intubation failure emerged. Moreover, the well-known undesirables side effects of cholinesterase inhibitors needing blunting by coadministration of muscarinic antagonists enlarged the odds of experiencing unwanted extra drug effects [3]. Further studies supported the use of sugammadex to reverse a life-threatening situation defined as "cannot intubate, cannot ventilate" [4]. It was a genuine revolutionary approach [5].Thus sugammadex appeared as a rescue drug. It was then used as the best, the most rapid and the safest if not the single solution to reverse curarization, although controversies as to the standard ofrapid sequence induction and intubation[6] are going on [7]. The odds were favorable and still are if it were not for certain voices to say "nay" to sugammadex as a routine drug based mainly on cost related issues.

Promoted advantages over the other muscle-relaxant antagonists were published, such as the salutary capability of reversing deeper levels of neuromuscular blockade [8].

This issue's article on the comparative effects of reversal of the neuromuscular blockade exerted by sugammadex compared to neostigmine following laparoscopic sleeve gastrectomy, study authored by a group of anaesthetists of the Wolfson Medical Central in Holon, Israel, focuses on postoperative residual curarization [9]. The hypothesis was that sugammadex might cause less postoperative residual curarization and respiratory complications. They compared two groups of obese patients anaesthetised for sleeve gastrectomy. The moderate neuromuscular block produced [one spontaneous twitch allowed throughout surgery) was obtained with rocuronium $0.6 \mathrm{mg} / \mathrm{kg}$ and maintained with boluses of 10-20 mg rocuronium if detecting more than one twitch. In case of aspiration risk, succiniycholine was used (dosed on total body weight). The patients have been de-curarized with either sugammadex or neostigmine. They used doses of 1.5 to $2.0 \mathrm{mg} / \mathrm{kg}$ of sugammadex and $2.5 \mathrm{mg} / \mathrm{kg}$ of neostigmine and looked for anything related to possible consequences of residual curarization. Pharmacokinetic studies recommend dosing rocuronium on ideal body weight (IBW), rather than on real body weight (RBW) based on its weak lipophilicity [10].

The groups significantly differed only as to the type of anesthesia used - total intravenous anaesthesia and fentanyl use most frequently associated with sugammadex but also history of obstructive sleep apnea syndrome (OSA). Being a retrospective study, we can only speculate that the type of anaesthesia was not randomly assigned but pendant of a certain preference for TIVA to the OSA patients.

A subgroup analysis in an enlarged sugammadex group - TIVA with remifentanyl versus TIVA with fentanyl - might have beheaded some of these speculations of a naïve mind such as mine. A possible explanation for the lack of difference between the 2 groups compared is due to the fact that in small doses, sugammadex may form complexes only with the rocuronium molecules within the central compartment and cannot sustain redistribution from peripheral to central compartments. According to a previously published study by Drobnik, the recommended dose for sugammadex is $4 \mathrm{mg} / \mathrm{kg}$, while anything else would be suboptimal [11].

\footnotetext{
* Correspondence to: Sanda-Maria Copotoiu, University of Medicine and Pharmacy of Tirgu Mures, 38 Gheorghe Marinescu street, Tirgu Mures, 540139, Romania. E-mail: sanda_copotoiu@yahoo.com
} 
It might just be that failure to identify differences in postoperative complications between the offering sugammadex and the old chap neostigmine is due to the blessed routine that prevents well trained anaesthetists to fall on the slippery slope of giving up a functioning and safe protocol of anaesthesia for the attractive (for good reasons) but expensive option.

A previously published study comparing prospectively enrolled patients submitted to elective sleeve gastrectomy under general anaesthesia and having a (body mass index) $\mathrm{BMI}>38 \mathrm{~kg} / \mathrm{m}^{2}$, compared reversal of the neuromuscular block obtained with rocuronium (0.6 $\mathrm{mg} / \mathrm{kg}$ ). They used either $2 \mathrm{mg} / \mathrm{kg}$ sugammadex of real body weigh (RBW), or $2 \mathrm{mg} / \mathrm{kg}$ on ideal body weight [12]. General anaesthesia was uniform, fentanyl, propofol, rocuronium and desflurane. Their end-point was the recovery time to T4/T1 of 0.9 after sugammadex based on the IBW in bariatric surgery [12]. They concluded that "sugammadex in a dose of $2 \mathrm{mg} / \mathrm{kg}$ of IBW facilitated rapid recovery from moderate rocuronium - induced neuromuscular block in morbidly obese patients". The dose was considered to be safe if used for IBW denominators. IBW in this study was calculated according to Broca's formula. We have to consider that in their cases, anaesthesia was induced with desflurane and that the number of patients included was considerable less compared to the Ezri study (179 patients enrolled). Moreover, the Ezri group calculated a sample size of 150 ( $n=75$ in each group) to provide an $80 \%$ power to detect a true, relative between group difference of partial recurarization [9].

The Ezri group admit that some of their patients have received suboptimal doses of sugammadex. Their study, although with the methodological limitations they pointed out, is important for it is:

Firstly, a good clinical practice experience on anaesthesia to morbidly obese patients for bariatric surgery, considering the reduced number of postoperative complications and the lack of serious adverse events.

A fair scientific medical study of the possible postoperative complications avoided by a cautious management of recurarization.

A proof that postoperative respiratory complications, although just a few, could not be linked or attributed to partial recurarization in the sugammadex group (112 patients) while there was one residual curarization in 67 patients receiving neostigmine.

Nevertheless, sugammadex is still in the frontline as the "escape drug" in obvious difficulties with intuba- tion and/or ventilation and for those who can afford it as a routine, it is a soothing drug for the anaesthetist.

\section{REFERENCES}

1. Booj LHDJ, De Boer HD, Van Egmond J. Reversal agents for nondepolarizing neuromuscular blockade: Reasons for and development of a new concept. Semin Anesth Periop Med Pain. 2002; 21:92-98.

2. Bom A, Bradley M, Cameron K, Clark JK, Van Egmond J, Feilden H, Mac Lean EJ, Muir AW, Palin R, Rees DC, Zhang M-Q. A novel concept of reversing neuromuscular block: Chemical encapsulation of rocuronium bromide by a cyclodextrin-based synthetic host. Angew Chem Int Ed Engl. 2002; 41:266-270.

3. De Boer HD, van Egmond J, van de Pol F, Bom A, Booj LHD. Chemical encapsulation of rocuronium by synthetic cyclodextrin derivatives: reversal of neuromuscular block in anaesthetized Rhesus monkeys. British J Anaesth. 2006; 92(2): 201-206.

4. De Boer HD, Driessen JJ, Marcus MAE, Kerkkamp H, Heeringa M, Klimek M. Reversal of Rocuronium - induced (1,2 mg/kg) Profound Neuromuscular Block by Sugammadex. A Multicenter, Dose-finding and Safety Study. Anesthesiology 2007; 107:239244.

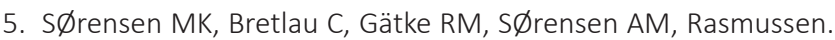
Rapid sequence induction and intubation with rocuroniumsugammadex compared with succinylcholine: a randomized trial. British J Anaesth. 2012; 108 (4): 682-689.

6. Kopman AF, Chin W, Cyriac J. Acceleromyography vs. electromyography: an ipsilateral comparison of the indirectly evoked neuromuscular response to train-of-four stimulation. Acta Anesthesiol Scan. 2005; 49: 316-322.

7. El-Orbany M, Connolly Lois A. Rapid Sequence Induction and Intubation: Current Controversy. Anesthesia and Analgesia. 2010; 110(5): 1318-1325

8. Zhang M-Q.Drug -specific cyclodextrins. The future of rapid neuromuscular block reversal, Drugs Future. 2003; 23:347-354.

9. Ezri T, Evron S, Petrov Irina, Schlechter P, Berlovich $Y$, Shimonov $\mathrm{M}$ : Residual curarization and postoperative respiratory complications following laparoscopic sleeve gastrectomy - the effect of reversal agents: sugammadex vs. neostigmine. J Crit Care Med. 2015;1(2):61-7.

10.Leykin Y, Pellis T, Lucca M, Lomangino G, Marzano B, Gullo A. The Pharmacodynamic effects of rocuronium when dosed according to real body weight or ideal body weight in morbidly obese patients. Anesthesia and Analgesia, 99 (4): 1086-1089, 2004.

11.Drobnik L, Sparr HJ, Thorn S-E, Khuenl-Brady Karin S, Rietbergeb $H$, Prins Martine E, Ullman J. A randomized simultaneous comparison of acceleromyography with the peripheral nerve stimulator for assessing reversal of rocuronium-induced neuromuscular blockade with sugammadex. Eur J Anesthesiol 2010; 27:866-873.

12.SanfillipoMaria, Alessandri F, Sousha AAWA, Sabba A, Cutolo Alessandra. Sugammadex and Ideal Body Weight in Bariatric Surgery. Review article. Anesthesiology Research and Practice, vol 213, ID 389782, http://dx.doi.org/10.1155/2013/389782. 